\title{
Proton transfer reactions for improved peptide characterisation
}

\section{Marko Rožman, Andrea Schneider and Simon J. Gaskell}

The combination of deprotonation (via ion/molecule and ion/ion reactions) and low-energy collision-induced dissociation (CID) has been explored for the enhanced characterisation of tryptic peptides via access to different precursor charge states. This approach allows instant access to fragmentation properties of singly and doubly protonated precursors (arising from the availability of mobile protons) in a single experiment. Considering both charge states extended our base of structurally informative data (in comparison with considering just a single charge state) due to generation of additional sequence ions and by obtaining supplementary structural information derived from selective cleavages. Roughly $37 \%$ of combined data sets (CID spectra of doubly and singly charged precursor) showed a greater database identification confidence than each set alone. Moreover, comparison between a number of sequence ions of the singly charged precursor and the doubly charged precursor provided a mean of distinguishing the two classes of tryptic peptides (arginine or lysine containing).

Keywords: ion/molecule reaction; ion/ion reaction; collision induced dissociation; peptide identification; charge state

\section{INTRODUCTION}

Tandem mass spectrometry is an essential tool for rapid protein identification in proteomics and systems biology. Currently, there are two complementary ways of tackling mass spectrometric protein analysis, either by the sequencing of intact proteins (the 'top-down' approach) or their peptides formed by proteolytic (usually tryptic) digestion (the 'bottom-up' approach). Despite the crucial importance of proteomics, our understanding of a number of aspects of the behaviour of peptide ions in the gas phase remains imperfect and therefore our optimisation of the analysis is correspondingly poor. One possible way to improve this is using ion/molecule and ion/ion reactions to gain further structural information.

Proton transfer reactions, based on deprotonation of multiprotonated protein/peptide ions via an interaction with strong bases, have involved deprotonation ${ }^{[1-5]}$ and H/D exchange $\mathrm{e}^{[5]}$ which provided insights into proton transfer properties (e.g. apparent proton affinity) $)^{[3]}$ and revealed information about secondary gas-phase structure (e.g. distinction of isomers). ${ }^{[4]}$ Other compounds, such as hydroiodic acid, show reactivity towards oligopeptide basic sites allowing useful information regarding basic site number to be obtained. ${ }^{[6]}$ Another nice example is the use of trimethoxy borate. Trimethoxy borate reacts with a phosphate moiety and thus can detect a phosphopeptide in a peptide mixture. ${ }^{[7]}$ Although bimolecular gas-phase chemistry can be used as a standalone tool, one can combine bimolecular (ion/molecule and ion/ion) and unimolecular (decomposition) chemistry. Regarding combining proton transfer reactions (PTRs) and collision-induced dissociation (CID), the best example is extensive work by McLuckey's group on charge manipulation of multiply charged ions (primarily proteins) prior and post CID. ${ }^{[8-18]}$ These studies have suggested that in the top-down approach, the dissociation channels are highly dependent on precursor ion charge state. Low and high charge states have shown relatively modest sequence coverage, while intermediate charge states provided the greatest sequence coverage.

While in the top-down strategy it is common to consider more than one precursor ion charge state to get better sequence coverage, ${ }^{[8-18]}$ the bottom-up analysis generally exploits the single charge state favoured by the ionisation method and/or the peptide length.

In this article, we explore the combination of PTRs with CID on smaller (tryptic) peptides, typical for bottom-up strategy. The PTRs were used to reduce the charge state of tryptic peptide ions generated by electrospray prior to tandem MS analysis. Thus, allowing us to consider information derived from two precursor charge states (singly and doubly protonated) and to exploit differences in fragmentation properties. Possible benefits of considering both charge states in a terms generation of additional sequence ions, obtaining supplementary structural information, distinguishing the two classes of tryptic peptide and consequently increase in the database identification confidence are explored.

\section{EXPERIMENTAL}

Analytes and reagents were obtained from Sigma-Aldrich (Dorset, UK) and used without further purification. Gas-phase reagents 

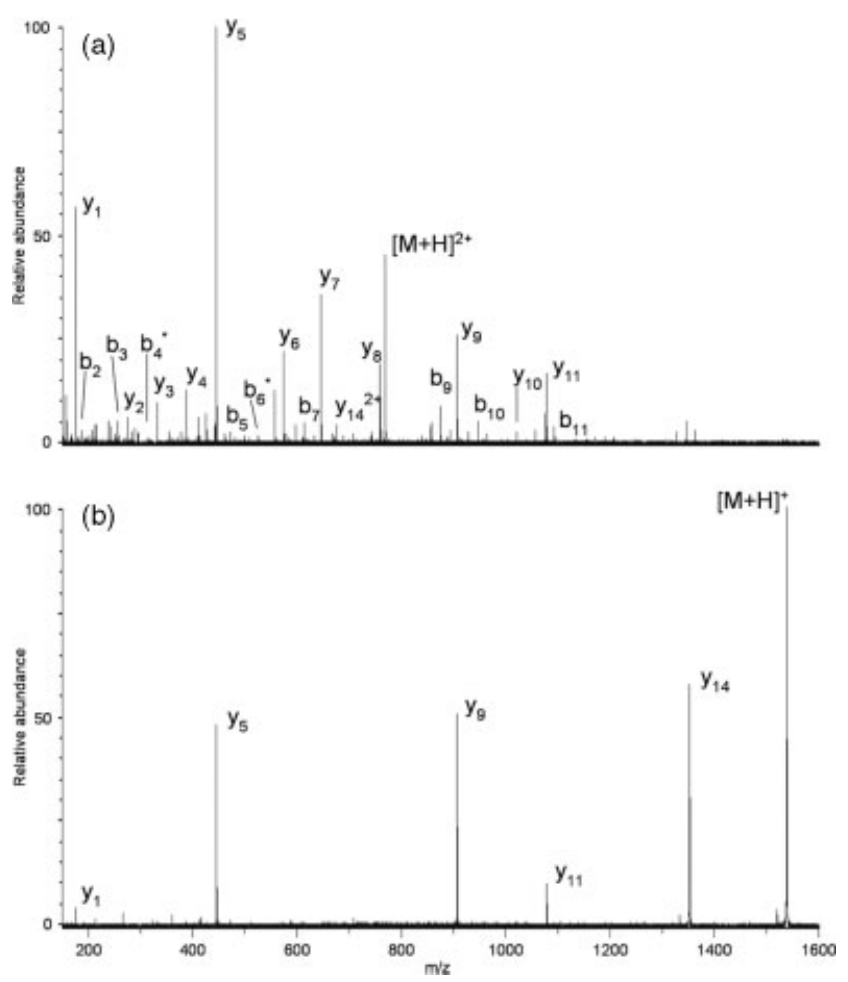

Figure 1. SORI-CID spectrum of doubly (a) and singly (b) protonated fibrinopeptide A human $\left(b_{n}{ }^{*}=b_{n}-\mathrm{H}_{2} \mathrm{O}\right)$.

employed in this study consisted of organic bases of known proton affinity (PA) and gas-phase basicity (GB). The reagents used were triethylamine $\left(P A=981.8 \mathrm{~kJ} \mathrm{~mol}^{-1}, \mathrm{~GB}=951 \mathrm{~kJ} \mathrm{~mol}^{-1}\right)_{\text {, }}^{[19]}$ 1,1,3,3-tetramethylguanidine (TMG; $P A=1031.6 \mathrm{~kJ} \mathrm{~mol}^{-1}, \mathrm{~GB}$ $\left.=997.4 \mathrm{~kJ} \mathrm{~mol}^{-1}\right)^{[19]}$ and 7-methyl-1,5,7-triazabicyclo[4.4.0]dec-5ene (MTBD; PA $=1062.7 \mathrm{~kJ} \mathrm{~mol}^{-1}, \mathrm{~GB}=1030.2 \mathrm{~kJ} \mathrm{~mol}^{-1}$ ). ${ }^{[19]}$ Peptide samples were made up to $10 \mu \mathrm{M}$ in water: methanol:acetic acid (50:50:1 by volume) and introduced into the electrospray ionisation (ESI) source by direct infusion at a flow rate of $100 \mu \mathrm{l} / \mathrm{h}$.

For automated analysis using ion/ion PTRs, standard tryptic digests of bovine serum albumin (BSA) and lysozyme were prepared using dithiotriethol/jodacetamide for reduction/alkylation in an $\mathrm{NH}_{4} \mathrm{HCO}_{3}$ buffer. Online separation was performed on a Dionex Ultimate 3000 nanoLC system (Amsterdam, the Netherlands) equipped with a $75 \mu \mathrm{m}$ i.d. column $(\mathrm{C} 18,3 \mu \mathrm{m}, 100 \AA$, PepMap, Dionex, Amsterdam, the Netherlands). In total, $100 \mathrm{fg}$ of digest was injected on column and separated using a 40-min gradient from 2 to $40 \%$ acetonitrile.

The combination of the ion/molecule PTRs and CID was performed on a 9.4 T Bruker Daltonics (Coventry, UK) Apex III Fourier transform ion cyclotron resonance (ICR) mass spectrometer equipped with an Apollo ESI source. Argon was employed for collisional cooling and as a collision gas for sustained offresonance irradiation (SORI) CID. The following experimental event sequence was applied. Briefly, ions were accumulated externally in a hexapole for $0.5-2 \mathrm{~s}$ before transfer to the ICR cell through ion optics. lons of interest were subsequently isolated and allowed to react with a neutral organic base of known PA and GB. Introduction of the basic compound into the ICR vacuum chamber through the pulse valve was followed by a delay (typically $\sim 4 \mathrm{~s}$ ) to allow the deprotonation reaction to occur and allow the system to pump down. Following charge reduction, ions of interest were isolated
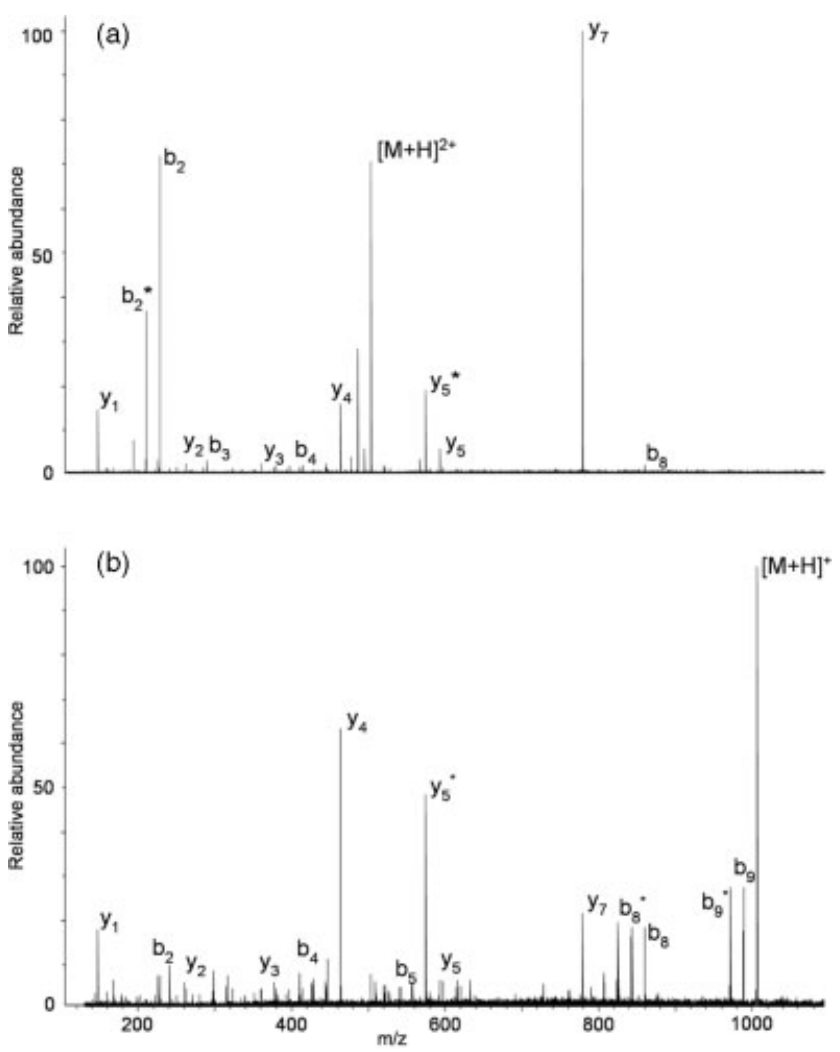

Figure 2. SORI-CID spectrum of doubly (a) and singly (b) protonated interleukin- $1 \beta$ fragment $\left(\mathrm{b}_{n}{ }^{*}=\mathrm{b}_{n}-\mathrm{H}_{2} \mathrm{O}, \mathrm{y}_{n}{ }^{*}=\mathrm{y}_{n}-\mathrm{H}_{2} \mathrm{O}\right)$.

and subjected to SORI-CID, with activation at $500-1000 \mathrm{~Hz}$ below their resonance frequencies. The trap plates of the ICR cell were held at $\sim 3 \mathrm{~V}$ for ion trapping and reduced to $\sim 1 \mathrm{~V}$ prior to detection.

The ion/ion PTRs were performed on an amaZon electron transfer reaction (ETD) ion trap system (Bruker Daltonik $\mathrm{GmbH}$, Bremen, Germany) which incorporates a negative chemical ionization $(\mathrm{Cl})$ source capable of providing reagent anions for both ETD and PTR. The acquisition software was set up in autoMSMS mode using two precursor ions with active exclusion on (precursor exclusion after one MSMS spectrum for $0.3 \mathrm{~min}$ ). MS spectra were acquired within a scan range from 300 to $1500 \mathrm{~m} / \mathrm{z}$ and a scan speed of $8100(\mathrm{~m} / \mathrm{z}) / \mathrm{s}$ using averages from five spectra. MSMS spectra were acquired within a scan range from 100 to $2500 \mathrm{~m} / \mathrm{z}$ and a scan rate of $32500(\mathrm{~m} / \mathrm{z}) / \mathrm{s}$ using averages from two spectra. For automated spectra generation, autoMSMS mode was set to alternate in between CID MS(2) and PTR/CID MS(3). Reaction time for PTR was set to $100 \mathrm{~ms}$.

Peptide ion identification was attempted using Mascot (Matrix Science Ltd., London, UK) database searching. For each peptide, three identifications were made; for CID spectra of a singly and doubly precursor as well as for $2^{+}-1^{+}$merged spectrum. The merged spectrum was obtained by combining peak lists of $2^{+}$ and $1^{+}$spectrum provided that the relative intensities of signals corresponding to the same mass were summed up.

\section{RESULTS AND DISCUSSION}

In a standard 'bottom-up' analysis, sequence information is generally obtained by tandem mass spectrometry of tryptic 


\begin{tabular}{|c|c|c|c|c|c|c|c|}
\hline \multirow{2}{*}{$\begin{array}{l}\text { Sequence } \\
\text { SIGSLAK }\end{array}$} & \multirow[t]{2}{*}{$z$} & \multirow{2}{*}{$\frac{\text { No. of } \mathrm{b} \text {-ions }}{1}$} & \multirow{2}{*}{$\frac{\text { No. of } y \text {-ions }}{1}$} & \multirow[t]{2}{*}{ Sequence-specific ions } & \multirow{2}{*}{$\frac{2 / 1^{\mathrm{a}}}{2 / 6}$} & \multicolumn{2}{|c|}{ Mascot ion score } \\
\hline & & & & & & - & - \\
\hline & 1 & 3 & 3 & & & - & \\
\hline \multirow[t]{2}{*}{ AFLNASR $^{b}$} & 2 & 3 & 5 & & $8 / 2$ & - & - \\
\hline & 1 & 1 & 1 & & & - & \\
\hline \multirow[t]{2}{*}{ AFLDASK $^{\mathrm{b}}$} & 2 & 2 & 3 & & $5 / 8$ & - & - \\
\hline & 1 & 4 & 4 & & & - & \\
\hline \multirow[t]{2}{*}{ PPGFSPFR $^{b}$} & 2 & 1 & 6 & & $7 / 3$ & - & - \\
\hline & 1 & 1 & 2 & & & - & \\
\hline \multirow[t]{2}{*}{ VQGEESNDK } & 2 & 4 & 6 & & $10 / 10$ & 38 & 37 \\
\hline & 1 & 4 & 6 & & & 23 & \\
\hline \multirow[t]{2}{*}{ CDPGYIGSR ${ }^{\mathrm{b}}$} & 2 & 1 & 4 & & $5 / 2$ & - & - \\
\hline & 1 & 0 & 2 & $y_{7}$ & & - & \\
\hline \multirow[t]{2}{*}{ HSDAVFTDNYTR } & 2 & 5 & 8 & & $13 / 2$ & 44 & 45 \\
\hline & 1 & 0 & 2 & $\mathrm{y}_{4}, \mathrm{y}_{9}$ & & 8 & \\
\hline \multirow[t]{2}{*}{ GAPVPYPDPLEPR ${ }^{\mathrm{b}}$} & 2 & 3 & 4 & & $7 / 2$ & - & - \\
\hline & 1 & 0 & 2 & $\mathrm{y}_{5}, \mathrm{y}_{2}$ & & - & \\
\hline \multirow[t]{2}{*}{ VEADIAGHGQEVLIR ${ }^{c}$} & 2 & 5 & 10 & & $15 / 5$ & 52 & 64 \\
\hline & 1 & 1 & 4 & $y_{4}, y_{11}, y_{13}$ & & 35 & \\
\hline \multirow[t]{2}{*}{ ADSGEGDFLAEGGGVR } & 2 & 9 & 12 & & $21 / 5$ & 76 & 94 \\
\hline & 1 & 0 & 5 & $\mathrm{y}_{5}, \mathrm{y}_{9}, \mathrm{y}_{11}, \mathrm{y}_{14}$ & & 41 & \\
\hline \multirow[t]{2}{*}{ GLSDGEWQQVLNVWGKC } & 2 & 2 & 5 & & $7 / 6$ & 20 & 22 \\
\hline & 1 & 2 & 4 & & & 11 & \\
\hline
\end{tabular}

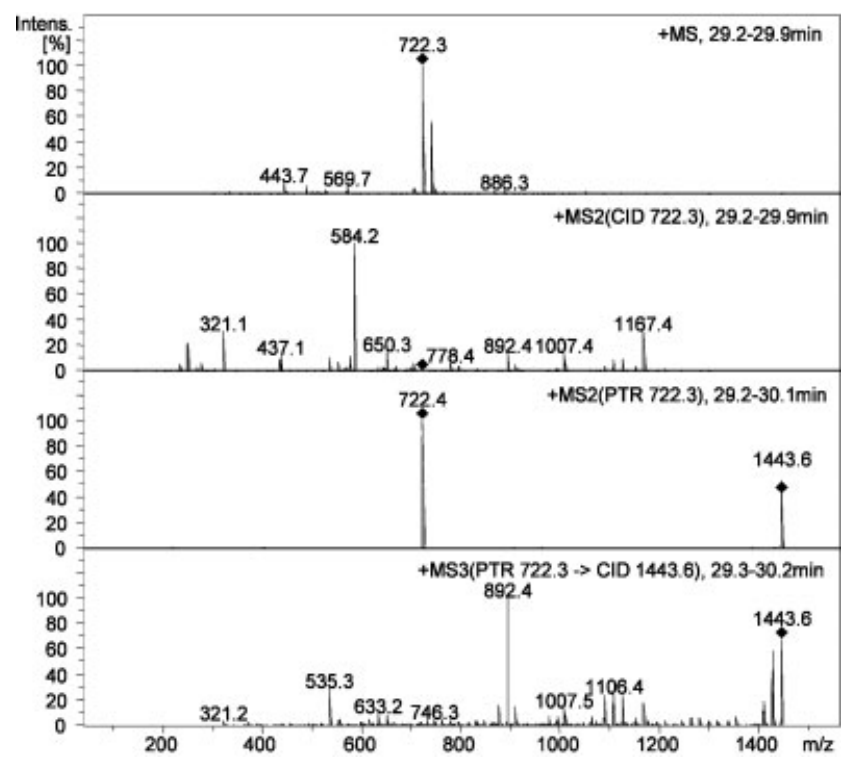

Figure 3. Data dependent MS and MS/MS spectra acquired for peptide YICDNQDTISSK (3: carbamidomethyl).

peptides. Depending on the ionisation method (MALDI or ESI) singly or multiply charged ions are produced and the subsequent analysis is focused on the predominant charge state produced. Generation of multiply charged (usually doubly) ions of tryptic peptides is beneficial because they fragment efficiently along the backbone due to location of one of the ionising protons on the backbone (with the other preferentially located on the terminal basic residue), resulting in a sequence of b-and y-type fragment ions. ${ }^{[20-23]}$ On the other hand, singly charged peptide ions (with no mobile protons) containing Asp, Glu and oxidised Cys show tendencies for selective cleavage of the amide bond C-terminal of the acid residue allowing the incorporation of additional sequencespecific information into database search parameters for enhanced identification. ${ }^{[23-26]}$

Figure 1 gives example of combining both strategies. Doubly protonated human fibrinopeptide A (ADSGEGDFLAEGGGVR) was mass selected and fragmented by low-energy CID. A range of fragment ions were produced representing multiple cleavage sites. In the following experiment, the doubly charged species was deprotonated in an ion/molecule reaction with triethylamine and the resulting singly charged ion was subjected to low-energy CID. The remaining proton is assumed to be located on the highly basic guanidino group of the Arg side-chain, so that that a 'mobile' proton is no longer available to promote backbone fragmentation. Elimination of one ionising proton induced major changes in mechanistic, energetic and kinetic aspects of the dissociation process, now favouring the formation of product ions $\left(\mathrm{y}_{5}, \mathrm{y}_{9}, \mathrm{y}_{11}\right.$ and $\left.\mathrm{y}_{14}\right)$ promoted by acidic side-chains allowing us obtain additional sequence-specific information.

A Mascot MS/MS ion search of using the doubly charged precursor product ion spectra identified two peptides (ADSGEGDFLAEGGGVR - score 76 and TKDEGTFIAEGGGVR - score 61) as significant. Merged data from $2^{+}$and $1^{+}$spectrum increased ADSGEGDFLAEGGGVR score to 94, while the TKDEGTFIAEGGGVR score remained the same. Use of sequence-specific information from CID spectra of the singly charged species, i.e. existence of four acidic residues in the peptide sequence, gives even greater confidence in ADSGEGDFLAEGGGVR sequence. 


\begin{tabular}{|c|c|c|c|c|c|c|c|}
\hline Sequence & $z$ & No. of b-ions & No. of $y$-ions & Sequence-specific ions & $2 / 1$ & Mascot & \\
\hline \multirow[t]{2}{*}{ IETMR } & 2 & 2 & 3 & & $5 / 2$ & 19 & 19 \\
\hline & 1 & 0 & 2 & & & 21 & \\
\hline \multirow[t]{2}{*}{ GACLLPK } & 2 & 5 & 5 & & $10 / 8$ & 46 & 42 \\
\hline & 1 & 4 & 4 & & & 33 & \\
\hline \multirow[t]{2}{*}{ LVTDLTK } & 2 & 5 & 7 & & $12 / 9$ & 51 & 28 \\
\hline & 1 & 5 & 4 & & & 25 & \\
\hline \multirow[t]{2}{*}{ DDSPDLPK } & 2 & 4 & 6 & & $10 / 5$ & 37 & 43 \\
\hline & 1 & 1 & 4 & & & 46 & \\
\hline \multirow[t]{2}{*}{ LCVLHEK } & 2 & 5 & 6 & & $11 / 9$ & 36 & 36 \\
\hline & 1 & 5 & 4 & & & 24 & \\
\hline \multirow[t]{2}{*}{ AEFVEVTK } & 2 & 6 & 7 & & $13 / 9$ & 41 & 39 \\
\hline & 1 & 5 & 4 & & & 45 & \\
\hline \multirow[t]{2}{*}{ YLYEIAR } & 2 & 5 & 6 & & $11 / 9$ & 52 & 45 \\
\hline & 1 & 5 & 4 & $\mathrm{y}_{3}$ & & 24 & \\
\hline \multirow[t]{2}{*}{ DLGEEHFK } & 2 & 6 & 5 & & $11 / 7$ & 36 & 42 \\
\hline & 1 & 3 & 4 & & & 36 & \\
\hline \multirow[t]{2}{*}{ QTALVELLK } & 2 & 6 & 7 & & $13 / 8$ & 41 & 41 \\
\hline & 1 & 5 & 3 & & & 34 & \\
\hline \multirow[t]{2}{*}{ NECFLSHK } & 2 & 6 & 6 & & $12 / 8$ & 24 & 33 \\
\hline & 1 & 3 & 5 & & & 30 & \\
\hline \multirow[t]{2}{*}{ SHCIAEVEK } & 2 & 7 & 7 & & $14 / 10$ & 34 & 41 \\
\hline & 1 & 6 & 4 & & & 51 & \\
\hline \multirow[t]{2}{*}{ LVNELTEFAK } & 2 & 8 & 9 & & $17 / 14$ & 61 & 43 \\
\hline & 1 & 7 & 7 & & & 29 & \\
\hline \multirow[t]{2}{*}{ SLHTLFGDELCK } & 2 & 9 & 10 & & $19 / 17$ & 53 & 58 \\
\hline & 1 & 8 & 9 & & & 54 & \\
\hline \multirow[t]{2}{*}{ YICDNQDTISSK } & 2 & 10 & 10 & & $20 / 16$ & 78 & 56 \\
\hline & 1 & 8 & 8 & & & 50 & \\
\hline \multirow[t]{2}{*}{ TCVADESHAGCEK } & 2 & 11 & 11 & & $22 / 14$ & 77 & 65 \\
\hline & 1 & 6 & 8 & & & 56 & \\
\hline \multirow[t]{2}{*}{ ETYGDMADCCEK } & 2 & 10 & 9 & & $19 / 15$ & 51 & 70 \\
\hline & 1 & 6 & 9 & & & 57 & \\
\hline \multirow[t]{2}{*}{ EYEATLEECCAK } & 2 & 10 & 8 & & $18 / 16$ & 49 & 49 \\
\hline & 1 & 7 & 9 & & & 66 & \\
\hline \multirow[t]{2}{*}{ VPQVSTPTLVEVSR } & 2 & 7 & 10 & & $17 / 3$ & 58 & 57 \\
\hline & 1 & 1 & 2 & & & 25 & \\
\hline \multirow[t]{2}{*}{ DDPHACYSTVFDK } & 2 & 9 & 8 & & $17 / 13$ & 32 & 44 \\
\hline & 1 & 4 & 9 & & & 49 & \\
\hline \multirow[t]{2}{*}{ YNGVFQECCQAEDK } & 2 & 12 & 12 & & $24 / 13$ & 53 & 54 \\
\hline & 1 & 6 & 7 & & & 51 & \\
\hline \multirow[t]{2}{*}{ ECCHGDLLECADDR } & 2 & 10 & 10 & & $20 / 3$ & 47 & 72 \\
\hline & 1 & 2 & 1 & & & 72 & \\
\hline
\end{tabular}

Figure 2 represents result of an analogous procedure employed on Lys-containing tryptic peptide interleukin- $1 \beta$ fragment 163-171 human (VQGEESNDK). Here, the singly charged precursor obtained via deprotonation reaction (also with triethylamine) is assumed to be protonated on the lysine amino group. Due to lower basicity of the Lys residue (thus the greater ease of mobilization of an ionizing proton) selective cleavage effects are less pronounced and more fragments are produced. Low-energy CID of the singly protonated precursor produced mainly similar fragments (in a terms of number and type) as doubly charged, however, with addition of $b_{5}$. MS/MS database search of using the doubly charged precursor returned two high scores, VQGEESNDK with score of 38 and QVFGTLANR with score of 35 . Merged $2^{+}$ and $1^{+}$data dropped VQGEESNDK score to 37, however, making it more significant due to the fact that second best score was now 19 for LNMSQVSVK sequence.

Equivalent experiments on a variety of tryptic and trypticlike peptides (results in Table 1) were conducted. Additionally, two other bases (TMG and MTBD) were also investigated and shown to induce deprotonation, in agreement with their higher gas-phase basicity (data not shown). Triethylamine remained the base of choice mainly because its lower boiling point made it more suitable for rapid introduction and evacuation from the ICR cell.

However, to generate more data and having in mind that ion/ion PTRs are more robust approach for charge manipulation, an automated LC-MS/MS run (with obtaining both $2^{+}$and $1^{+}$ CID spectra) was conducted on two tryptic digests (BSA and 


\begin{tabular}{|c|c|c|c|c|c|c|c|}
\hline Sequence & $z$ & No. of b-ions & No. of $y$-ions & Sequence-specific ions & $2 / 1$ & Mascot & \\
\hline \multirow[t]{2}{*}{ HGLDNYR } & 2 & 5 & 6 & & $11 / 6$ & 38 & 36 \\
\hline & 1 & 3 & 3 & $y_{3}$ & & 25 & \\
\hline \multirow[t]{2}{*}{ WWCNDGR } & 2 & 4 & 6 & & $10 / 3$ & 23 & 21 \\
\hline & 1 & 1 & 2 & $y_{2}$ & & 19 & \\
\hline \multirow[t]{2}{*}{ GTDVQAWIR } & 2 & 7 & 7 & & $14 / 2$ & 50 & 59 \\
\hline & 1 & 0 & 2 & $y_{6}$ & & 30 & \\
\hline \multirow[t]{2}{*}{ GYSLGNWVCAAK } & 2 & 10 & 10 & & $20 / 10$ & 81 & 77 \\
\hline & 1 & 4 & 6 & & & 28 & \\
\hline \multirow[t]{2}{*}{ FESNFNTQATNR } & 2 & 9 & 10 & & $19 / 2$ & 84 & 77 \\
\hline & 1 & 0 & 2 & $y_{10}$ & & 34 & \\
\hline \multirow[t]{2}{*}{ NTDGSTDYGILQINSR } & 2 & 10 & 11 & & $21 / 2$ & 63 & 70 \\
\hline & 1 & 0 & 2 & $\mathrm{y}_{9}, \mathrm{y}_{13}$ & & 65 & \\
\hline
\end{tabular}

lysozyme). During LC-MS/MS run, most abundant signals were automatically selected and the low-energy CID spectra were generated. After that, the same ion was charge reduced via PTR and again, the low-energy CID spectrum was generated. Figure 3 gives example of data-dependent acquired MS and MS/MS spectra for one tryptic peptide from BSA digest. Tables 2 (BSA) and 3 (lysozyme) summarise results for each peptide identified from mixture.

Taken together results from Tables 1 to 3 allow several conclusions to be drawn. Depending on C-terminal amino acid, peptides behave similar to examples illustrated in Figs 1 (Arg terminated) and 2 (Lys terminated). Applied strategy of combining information from singly and doubly protonated precursor may improve peptide identification due to the generation of additional sequence ions and/or obtaining supplementary structural information derived from selective cleavages. The analysed peptides (37.5\%) have shown increase in the identification confidence for merged $2^{+}-1^{+}$spectra (comparing to $2^{+}$spectra), even though Mascot database search does not incorporate knowledge derived from selective cleavages (e.g. location of acidic residues). Another $37.5 \%$ of the data set remained in the same range (within \pm 2 points), while for the remaining $25 \%$, identification confidence decreased. Confidence decrease is more often observed for Lys-containing peptides (30\% for Lys and 17\% for Arg). This may be explained by a fact that the singly protonated Lys-terminated peptides produce more unidentified peaks and low abundance ions (e.g. Figure 2), which may obstruct an identification process.

A more specific observation regarding the singly protonated Lys-terminated peptides is that they generate similar or somewhat greater number of fragment ions than the doubly protonated analogues, in contrast to the behaviour of Arg-terminated peptides. The observation is attributable to the lower energy requirement for mobilisation of an ionising proton from Lys than Arg residues, reflecting the lower gas-phase basicity of Lys. $^{[22]}$ Comparison of tandem mass spectra resulting from singly charged versus doubly charged precursor ions therefore allows speculation about the $\mathrm{C}$ terminal amino acid residue. For protonated Arg-terminated peptide ions, the ratio of number of observed fragments from doubly and singly charged precursors tend to be $>2$, whereas this ratio is $\leq 2$ for Lys-terminated peptides. Although the presence of $m / z 147$ or $175 \mathrm{y}_{1}$ ions is usually a good indication about the nature of $\mathrm{C}$-terminal amino acid residue, this comparison could be useful for ion-trap instruments, i.e. where a low mass/charge cut-off is applied.

\section{CONCLUSION}

The employed combination of deprotonation reactions and standard tandem mass spectrometry methods (low-energy CID) is shown to be an effective way of generating additional primary sequence information. Two sets of data are obtained, one from doubly and other from singly charged precursor, exploiting benefits of cleavage proximal to, and remote from, the site of protonation. The applied strategy has a potential to improve peptide identification due to the generation of additional sequence ions and/or from obtaining supplementary structural information derived from selective cleavages. In 37.5\% cases combined data set (CID spectra from doubly and other singly charged precursor) had greater identification confidence than commonly used doubly charged one. It is demonstrated that comparison of the fragment ion spectra from doubly and singly charged precursor ions points to a distinction between Arg- and Lys-terminated tryptic peptides.

Although the strategy presented here needs to be optimised and generalised, the data suggest that the use of PTRs may improve peptide characterisation without significant increase in the workload. Strength of the discussed strategy is the relative ease of applying PTRs in a range of trapping mass spectrometers, without the requirement for extensive modifications.

\section{Acknowledgements}

Helpful discussions with members of the Michael Barber Centre for Mass Spectrometry are gratefully acknowledged. The Engineering and Physical Sciences Research Council supported this work (Grant EP/D013615/1).

\section{REFERENCES}

[1] S. A. McLuckey, G. J. Van Berkel, G. L. Glish. Reactions of dimethylamine with multiply charged ions of cytochrome c. J. Am. Chem. Soc. 1990, 112, 5668.

[2] E. R. Williams. Proton transfer reactivity of large multiply charged ions. J. Mass Spectrom. 1996, 31, 831.

[3] A. G. Harrison. The gas-phase basicities and proton affinities of amino acids and peptides. Mass Spectrom. Rev. 1997, 16, 201.

[4] C. J. Cassady, S. R. Carr. Elucidation of isomeric structures for ubiquitin $[\mathrm{M}+12 \mathrm{H}]^{12+}$ ions produced by electrospray ionization mass spectrometry. J. Mass Spectrom. 1996, 31, 247. 
[5] M. K. Green, C. B. Lebrilla, Ion-molecule reactions as probes of gasphase structures of peptides and proteins. Mass Spectrom. Rev. 1997, 16, 53.

[6] J.L.Stephenson Jr., S. A. McLuckey. Counting basic sites in oligopeptides via gas-phase ion chemistry. Anal. Chem. 1997, 69, 281.

[7] Y. Pyatkivskyy, V. Ryzhov. Coupling of ion-molecule reactions with liquid chromatography on a quadrupole ion trap mass spectrometer. Rapid Commun. Mass Spectrom. 2008, 22, 1288.

[8] J. L. Stephenson Jr., B. J. Cargile, S. A. McLuckey. Ion trap collisional activation of disulfide linkage intact and reduced multiply protonated polypeptides. Rapid Commun. Mass Spectrom. 1999, $13,2040$.

[9] T. G. Schaaff, B. J. Cargile, J. L. Stephenson Jr., S. A. McLuckey. Ion trap collisional activation of the $(\mathrm{M}+2 \mathrm{H})^{2+}-(\mathrm{M}+17 \mathrm{H})^{17+}$ ions of human hemoglobin $\beta$-chain. Anal. Chem. 2000, 72, 899.

[10] G. E. Reid, J. Wu, P. A. Chrisman, J. M. Wells, S. A. McLuckey. Chargestate-dependent sequence analysis of protonated ubiquitin ions via ion trap tandem mass spectrometry. Anal. Chem. 2001, 73, 3274.

[11] K. A. Newton, P. A. Chrisman, J. M. Wells, G. E. Reid, S. A. McLuckey. Gaseous apomyoglobin ion dissociation in a quadrupole ion trap: $[\mathrm{M}+2 \mathrm{H}]^{2+}-[\mathrm{M}+21 \mathrm{H}]^{21+}$. Int. J. Mass Spectrom. 2001, 212, 359.

[12] B. J. Engel, P. Pan, G. E. Reid, J. M. Wells, S. A. McLuckey. Charge state dependent fragmentation of gaseous protein ions in a quadrupole ion trap: bovine ferri-, ferro-, and apo-cytochrome c. Int. J. Mass Spectrom. 2002, 219, 171.

[13] G. E. Reid, J. L. Stephenson Jr., S. A. McLuckey. Tandem mass spectrometry of ribonuclease $\mathrm{A}$ and $\mathrm{B}$ : $\mathrm{N}$-linked glycosylation site analysis of whole protein ions Anal. Chem. 2002, 74, 577.

[14] J.M. Hogan, S.A.McLuckey. Charge state dependent collisioninduced dissociation of native and reduced porcine elastase. J. Mass Spectrom. 2003, 38, 245.

[15] K. A. Newton, S. J. Pitteri, M. Laskowski, S. A. McLuckey. Effects of Single Amino Acid Substitution on the Collision-Induced Dissociation of Intact Protein lons:Turkey Ovomucoid Third Domain. J. Proteome Res. 2004, 3, 1033.

[16] Y. Xia, X. Liang, S. A. McLuckey. Ion trap versus low-energy beamtype collision-induced dissociation of protonated ubiquitin ions. Anal. Chem. 2006, 78, 1218.
[17] D. J. Watson, S. A. McLuckey. Charge state dependent ion trap collision-induced dissociation of reduced bovine and porcine trypsin cations. Int. J. Mass Spectrom. 2006, 255-256, 53.

[18] C. Chanthamontri, J. Liu, S. A. McLuckey. Charge state dependent fragmentation of gaseous $\alpha$-synuclein cations via ion trap and beam-type collisional activation. Int. J. Mass Spectrom. 2009, 283, 9.

[19] E. P. Hunter, S. G. Lias. Evaluated gas phase basicities and proton affinities of molecules: an update. J. Phys. Chem. Ref. Data 1998, 27, 413.

[20] O. Burlet, R. S. Orkiszewski, K. D. Ballard, S. J. Gaskell. Charge promotion of low energy fragmentations of peptide ions. Rapid Commun. Mass Spectrom. 1992, 6, 658.

[21] K.A. Cox, S. J. Gaskell, M. Morris, J. Whiting. Role of the site of protonation in the low-energy decompositions of gas-phase peptide ions. J. Am. Soc. Mass Spectrom. 1996, 7, 522.

[22] A. R. Dongre, J. L. Jones, A. Somogyi, V. H. Wysocki. Influence of peptide composition, gas-phase basicity, and chemical modification on fragmentation efficiency: evidence for the mobile proton model. J. Am. Chem. Soc. 1996, 118, 8365.

[23] Y.Y. Huang, J. M. Triscari, G.C. Tseng, L. Pasa-Tolic, M. S. Lipton, R. D. Smith, V. H. Wysocki. Statistical characterization of the charge state and residue dependence of low-energy CID peptide dissociation patterns. Anal. Chem. 2005, 77, 5800.

[24] G. Tsaprailis, A. Somogyi, E. N. Nikolaev, V. H. Wysocki. Refining the model for selective cleavage at acidic residues in argininecontaining protonated peptides. Int. J. Mass Spectrom. 2000, 195-196, 467.

[25] A. G. Sullivan, F. L. Brancia, R. Tyldesley, R. Bateman, K. Sidhu, S. J. Hubbard, S. G. Oliver, S. J. Gaskell. The exploitation of selective cleavage of singly protonated peptide ions adjacent to aspartic acid residues using a quadrupole orthogonal time-of-flight mass spectrometer equipped with a matrix-assisted laser desorption/ionization source. Int. J. Mass Spectrom. 2001, 210-211, 665.

[26] G. Tsaprailis, H. Nair, A. Somogyi, V. H. Wysocki, W. Zhong, J.H. Futrell, S. G. Summerfield, S. J. Gaskell. Influence of secondary structure on the fragmentation of protonated peptides. J. Am. Chem. Soc. 1999, 121, 5142. 